\title{
Computational Analysis of Glycerol Menthonide Using Spartan '04
}

\author{
Anthony Kiessling, Carissa Ganong and Ashley Johnson \\ Mansfield University \\ Mansfield, Pennsylvania 16933 USA
}

Received: July 11, 2008 Accepted: September 8, 2008

Glycerol menthonide has been reported in the literature and has been prepared by reaction of menthone with glycerol under acid catalysis. The menthonide was originally prepared as an additive to spearmint gum by a chemist at Wrigley's Inc. No further chemical analysis of the menthonide has been reported in the literature. However, glycerol menthonide should be a mixture of up to 6 isomers. Spartan ' 04 was used to determine the heat of formation of each isomer in an attempt to model the reaction mixture. This information was then compared with $\mathrm{GC} / \mathrm{MS}$ analysis of the product mixture. The isolation of one of the stereoisomers of glycerol menthonide is also reported.

\section{INTRODUCTION}

Wrigley's Inc. holds the patent for glycerol menthonide, a spiroketal used to increase the duration of flavor in spearmint gum. Glycerol menthonide has a BP of 135$140{ }^{\circ} \mathrm{C}$ at $2 \mathrm{~mm} \mathrm{Hg}$. Except for the original patent, no experimental work with glycerol menthonide is recorded in the chemical literature. The reaction theoretically yields six isomers depending on which two of the three hydroxyl groups of the glycerol are involved in forming the spiroketal and the relative stereochemistry in the product. The six possible isomers are shown below in Scheme 1 and labeled $2 a-2 f$. Molecular


2a

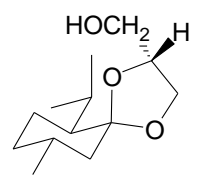

$2 c$

modeling programs like Spartan '04 offer the possibility of exploring the product mixture [1].

\section{RESULTS AND DISCUSSION}

Reaction between menthone and glycerol in acid should proceed by standard acetal mechanism. Once protonated the menthone would be attacked by one of the three hydroxyl groups on glycerol then eliminate water to yield a carbocation stabilized by the adjacent oxygen. There are only two possible structures for the carbocation that is formed as shown below (Scheme 2). The difference between the



2b

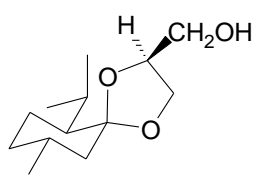

2d

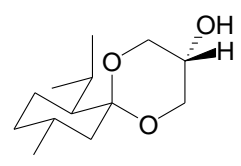

2e



Scheme 1. 
<smiles>CC1CCCC1OC(CO)CO</smiles>

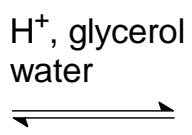

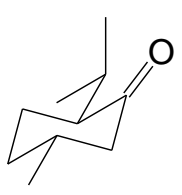
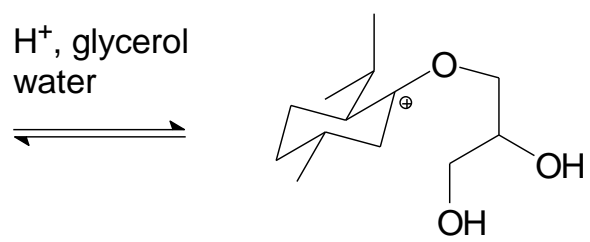

\section{Scheme 2.}

two is whether the primary or secondary hydroxyl group attacks the protonated menthone. These two carbocations ought to be in equilibrium through the menthone under the conditions of the reaction. Subsequent attack by one of the remaining hydroxyl groups yields a spiroketal. These remaining steps should also be equilibrium steps and therefore the isomeric products of glycerol menthonide should be in a dynamic equilibrium with each other. For these reasons the product mixture is under thermodynamic control and molecular modeling offers an opportunity to predict the reaction mixture.

Spartan '04 was used to calculate $\Delta \mathrm{Hf}$ for the six isomers shown in Scheme 1. The Hartree-Fock mode and 6-31G*, MMFF conformer and AM1 settings were used. Since $\Delta S$ is presumed to equal zero, $\Delta \mathrm{H}_{\mathrm{f}}$ was assumed to be nearly identical to $\Delta \mathrm{G}_{\mathrm{f}}$, from which the $\mathrm{K}_{\mathrm{eq}}$ and then the theoretical product proportion of each isomer were calculated. The results of the Spartan calculations are summarized in Table 1 below. Isomer $2 \mathrm{a}$ was identified as the lowest energy isomer and should be the major component of the reaction mixture. The difference in energy was calculated for the remaining 5 isomers. It is interesting to note that the two 6-membered spiroketals, $2 e \& 2 f$, are the highest in energy and therefore the least stable and least likely to be present in the reaction mixture. It is also interesting to note that there is little difference between the four 5-membered spiroketals, $2 \mathrm{a}-2 \mathrm{~d}$.

A second set of calculations was done by Dr. Warren Hehre of Wavefunction Inc. [2]. These calculations were based on B3LYP $6-31 G^{*}$ set which was not available in Spartan '04. These calculations were then treated as before to yield a ratio of products. Isomer $2 a$ is still the most stable although the relative proportion is less. Isomer $2 \mathrm{f}$ is still the least stable although the other 6-membered spiroketal is now more similar to the 5-membered spiroketals in its stability and proportion in the reaction mixture. The difference between the two sets of calculated data seems to be a result of using two different basis sets.

To compare the theoretical studies with the actual reaction mixture the glycerol menthonide was prepared according to published procedure [3]. This afforded a colorless, viscous oil, which proved difficult to analyze by GC/MS. We suspected the

\begin{tabular}{|c|c|c|c|c|}
\hline Isomer & $\begin{array}{c}\Delta \mathbf{G}_{\mathbf{f}} \\
\mathbf{( k J )}\end{array}$ & $\mathbf{K}_{\text {eq }}$ & $\begin{array}{c}\text { Ratio of } \\
\text { products }\end{array}$ & **Ratio (B3LYP 6-31G*) \\
\hline $2 \mathrm{f}$ & 13.428 & 0.0147 & 0.0049 & $<0.01$ \\
\hline $2 \mathrm{e}$ & 8.433 & 0.0708 & 0.0235 & 0.17 \\
\hline $2 \mathrm{c}$ & 1.479 & 0.6284 & 0.2088 & 0.17 \\
\hline $2 \mathrm{~b}$ & 1.406 & 0.6431 & 0.2137 & 0.19 \\
\hline $2 \mathrm{~d}$ & 1.361 & 0.6522 & 0.2167 & 0.22 \\
\hline $2 \mathrm{a}$ & & 1.000 & 0.3323 & 0.25 \\
\hline
\end{tabular}

Table 1.

${ }^{* *}$ calculated by Warren Hehre 




1

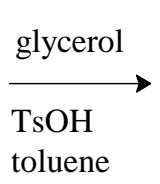

reflux



2a
+ isomers

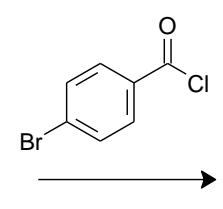

pyridine<smiles>CC1CCC2(C)CC1CC(C)(C)C21OC[C@@H](COC(=O)c2ccc(Br)cc2)O1</smiles>

3a<smiles>O=C(O)OCCCCCCCCO</smiles><smiles>CC1CCC2(C)CC1CC21OC[C@H](CO)O1</smiles>

2a glycerol

$\longrightarrow \quad 2 a+$ isomers reflux

\section{Scheme 3.}

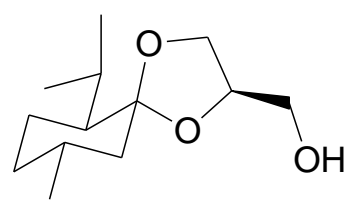

2a

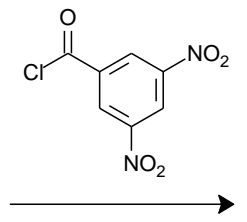

Pyridine<smiles></smiles>

\section{Scheme 4.}

remaining hydroxyl group was causing difficulties in separation of the isomers, so the product mixture was treated with 4bromobenzoyl chloride to yield the 4bromobenzoate ester ( $3 a+$ isomers). When the mixture of esters was subjected to analysis by GC/MS four peaks were revealed in nearly a $1: 1: 1.4: 1.8$ ratio. This was very similar to the calculated ratio of $1: 1: 1: 1.6$; however, at this time the identity of all the peaks has not been determined.

To test whether the isomers are in equilibrium under the reaction conditions it was necessary to separate isomer $2 a$ from the other isomers. This was made possible through flash chromatography of the 4bromobenzoate derivative mixture. Isomer 2a was chosen because its corresponding 4bromobenzoate derivative, 3a, happened to have the highest $R_{f}$ and therefore was both the first isomer off the column and also the purest. Spiroketal $3 a$ was isolated in 17\% yield after chromatography. Some of $3 a$ trails into the next isomer during chromatography and it has not been possible to remove all of $3 a$ from the mixture 
of isomers in one column but should be possible in repeated chromatography. Pure glycerol menthonide $2 \mathrm{a}$ was then prepared from $3 a$ by methanolysis. Pure $2 a$ was added to toluene, p-toluenesulfonic acid, and heated to reflux for 2 hours. The resulting mixture was isolated and treated with 4-bromobenzoyl chloride as before. Analysis of the resulting mixture proved that all four isomers of glycerol menthonide were present as the 4-bromobenzoate derivative. This indicated that the four isomers were indeed under thermodynamic control under these conditions.

The absolute structure of glycerol menthonide $2 \mathrm{a}$ is known through the $\mathrm{x}$-ray diffraction of its 3,5-dintrobenzoate derivative. Spiroketal $3 a$ is a solid but did not produce a crystal that would yield $x$-ray diffraction data. Using a fresh sample of pure spiroketal $2 \mathrm{a}$ the 3,5-dinitrobenzoate derivative, $4 \mathrm{a}$, was prepared (Scheme 4). The 3,5-dinitrobenzoate derivative did produce a crystal of sufficient quality to yield $x$-ray diffraction data [4]. The absolute stereochemistry of spiroketals $3 a$ and $2 a$ are known through the data for spiroketal $4 a$.

\section{CONCLUSION}

Spartan '04 provided a method to theoretically model a system of isomers under thermodynamic control. Through two sets of data Spartan '04 predicted that either 4 or 5 of the 6 possible isomers should be present in detectable quantities at equilibrium. The actual reaction mixture once converted to the 4-bromobenzoate derivative shows 4 isomers to be present by $\mathrm{GC} / \mathrm{MS}$. At this time the identity of all four isomers is unknown however one of them has been determined to be structure $2 a$ through its 3,5-dinitrobenzoate derivative.4 Work is continuing to determine the exact structure of each of the other isomers through the crystal structure of a derivative. Experimental

All chemicals were purchased through ThermoFisher Inc. and used without further purification. Glycerol menthonide was prepared according to published procedure. GC/MS data was obtained using a Varian CP 3800 with Saturn 2000 ion trap MS. Column: Varian CP 5860, WCOT fused silica $30 \mathrm{~m} \times 0.25 \mathrm{~mm}$, coating CP-Sil. Carrier gas: He $1.2 \mathrm{~mL} / \mathrm{min}$. Program $A$ : initial temperature $200{ }^{\circ} \mathrm{C}$, ramp $20{ }^{\circ} \mathrm{C} / \mathrm{min}$ to $250^{\circ} \mathrm{C}$ hold $14.5 \mathrm{~min}$. Program B: initial temperature $200{ }^{\circ} \mathrm{C}$, ramp $20^{\circ} \mathrm{C} / \mathrm{min}$ to 250 ${ }^{\circ} \mathrm{C}$ hold $14.5 \mathrm{~min}$. Program C: initial temperature $50{ }^{\circ} \mathrm{C}$, ramp $20{ }^{\circ} \mathrm{C} / \mathrm{min}$ to 250 ${ }^{\circ} \mathrm{C}$ hold 20 minutes. NMR data were obtained at Bucknell University using a Varian $600 \mathrm{MHz}$ instrument and $\mathrm{CDCl} 3$, data are reported as ppm from TMS and coupling constants are in $\mathrm{Hz}$. Melting points were obtained on a MelTemp and are uncorrected. TLC was done with Analtech 2520 plates.

\section{a. Spiroketal 3a}

In a $25 \mathrm{~mL}$ round bottom flask were placed glycerol menthonide (1.0 g, 4.4 $\mathrm{mmol})$, 4-bromobenzoyl chloride $(1.1 \mathrm{~g}, 5.0$ $\mathrm{mmol}$ ) and pyridine $(3 \mathrm{~mL})$. The flask was fitted with an air reflux condenser, drying tube and a magnetic stir bar. The flask was heated to reflux while stirring for 2 hours. The contents of the flask were then added to water $(10 \mathrm{~mL})$ and MTBE $(20 \mathrm{~mL})$ and separated. The aqueous layer was extracted twice with MTBE $(20 \mathrm{~mL})$. The combined organic layers were washed with $10 \% \mathrm{HCl}$ ( $2 \times 15 \mathrm{~mL}), 10 \% \mathrm{Na}_{2} \mathrm{CO}_{3}(2 \times 15 \mathrm{~mL})$ and saturated $\mathrm{NaCl}(15 \mathrm{~mL})$ dried over $\mathrm{MgSO}_{4}$ and the solvent removed under vacuum to yield the crude product as an oily solid. Flash chromatography $(3 \%$ ethyl acetate/petroleum ether) yielded pure compound as an oil (307 mg, 17\%) that solidified on standing and could be further purified by recrystallization from methanol/water to yield a white needle $\mathrm{mp}$ $54-55{ }^{\circ} \mathrm{C}$. TLC: $R_{f}=0.56$ in $7 \%$ ethyl acetate/petroleum ether. $\mathrm{GC}: \mathrm{R}_{\mathrm{t}}=12.01$ min Program A. IR: 2951, 1722, 1267, 1096, 1012, 845, 755. MS: 412 (13), 410 (13), 397 (16), 395 (16), 355 (19), 353 (18), 327 (100), 325 (98), 185 (28), 183 (28), 69 (34), expected for $\mathrm{C}_{20} \mathrm{H}_{27} \mathrm{BrO}_{4} 410.10$.

\section{b. Spiroketal 2a}

In a $10 \mathrm{~mL}$ reaction vial were placed spiroketal $3 \mathrm{a}$ (364 mg, $0.893 \mathrm{mmol}), \mathrm{K}_{2} \mathrm{CO}_{3}$ (136 mg, $0.99 \mathrm{mmol})$, methanol $(5 \mathrm{~mL})$ and a spin vane. The reaction was stirred at room temperature for 1 hour. The contents of the vial were added to water $(5 \mathrm{~mL})$ and diethyl ether $(5 \mathrm{~mL})$ and separated. The aqueous layer was extracted with diethyl 
ether $(2 \times 5 \mathrm{~mL})$. The combined organic layers were dried with $\mathrm{Na}_{2} \mathrm{SO}_{4}$ and the solvent removed under vacuum to yield the crude product as an oil $(335 \mathrm{mg})$. Flash chromatography $\quad(15 \% \quad$ ethyl acetate/petroleum ether) yielded methyl 4bromobenzoate $(0.155 \mathrm{mg}, 0.719 \mathrm{mmol}$, $80 \%)$ first and then the product $(149 \mathrm{mg}$, $0.655 \mathrm{mmol}, 73 \%$ ) as a colorless oil. TLC: $\mathrm{Rf}$ $=0.44$ with $20 \%$ ethyl acetate/petroleum ether. GC: $R_{t}=8.901$ min Program C. MS: MI 228 (11), 213 (21), 171 (25), 143 (100), 69 (34), expected for $\mathrm{C}_{13} \mathrm{H}_{24} \mathrm{O}_{3}, 228.33$.

\section{c. Spiroketal $4 \mathrm{a}$}

In a $25-\mathrm{mL}$ round bottom flask were placed spiroketal 2a $(0.50 \mathrm{~g}, 2.19 \mathrm{mmol})$, 3,5-dinitrobenzoyl chloride $(0.230 \mathrm{~g}, 2.4$ $\mathrm{mmol})$, and pyridine $(4 \mathrm{~mL})$. The flask was fitted with a reflux condenser, drying tube and a stir bar then heated to reflux for 1 hour. The reaction mixture was added to water $(10 \mathrm{~mL})$ and stirred. A yellowish-white solid (.405 g, $0.95 \mathrm{mmol}, 43 \%)$ was collected by vacuum filtration. Recrytallization with methanol/water yielded a while needle (mp $\left.95-96^{\circ} \mathrm{C}\right)$. TLC: $R_{f}=0.45$ with $7 \%$ ethyl acetate/petroleum ether. ${ }^{13} \mathrm{C}$ NMR: $162.4, \quad 133.5, \quad 129.5,122.6,114.0$,
$74.0,66.7,66.0,49.8,45.8,34.3,30.8,24.9$ 23.5, 23.2, 22.0, 18.5. ${ }^{1} \mathrm{H}$ NMR: $9.25(1 \mathrm{H}, \mathrm{t}$, $\mathrm{J}=2.1 \mathrm{~Hz}), 9.19(2 \mathrm{H}, \mathrm{d}, \mathrm{J},=2.4), 4.59(1 \mathrm{H}$, $\mathrm{dd}, \mathrm{J}=11.7,3.9), 4.51(1 \mathrm{H}, \mathrm{dd}, \mathrm{J}=11.4$, 5.4), $4.45(1 \mathrm{H}, \mathrm{m}), 4.22(1 \mathrm{H}, \mathrm{dd}, \mathrm{J}=8.7$, 6.3), $3.79(1 \mathrm{H}, \mathrm{t}, \mathrm{J}=8.4), 2.08(1 \mathrm{H}, \mathrm{m}), 1.74$ $(2 \mathrm{H}, \mathrm{m}), 1.65(2 \mathrm{H}, \mathrm{m}), 1.39(2 \mathrm{H}, \mathrm{m}), 1.17$ $(1 \mathrm{H}, \mathrm{t}, \mathrm{J}=12.9), 0.94(3 \mathrm{H}, \mathrm{d}, \mathrm{J}=7.2), 0.88$ $(7 \mathrm{H}, \mathrm{m}) . \mathrm{GC}: \mathrm{R}_{\mathrm{t}}=13.50$ min Program B. MS: MI 422 (2), 407 (18), 365 (16), 337 (100), 195 (22), 69 (26), $\mathrm{C}_{20} \mathrm{H}_{26} \mathrm{~N}_{2} \mathrm{O}_{8}, 422.44$.

\section{ACKNOWLEDGEMENTS.}

We wish to thank Dr. Doug Taber of the University of Delaware for many helpful discussions and Dr. David Rovnyak of Bucknell University for help in obtaining the NMR data. We also would like to thank the FPDC of Mansfield University for their support of this work.

\section{REFERENCES}

1. Wavefunction Inc., Irvine, CA, www.wavefun.com

2. Personal communication.

3. Greenberg, M. US Patent: 5, 977, 166.

4. Diffraction data has been accepted for publication in Acta Cryst $E$.

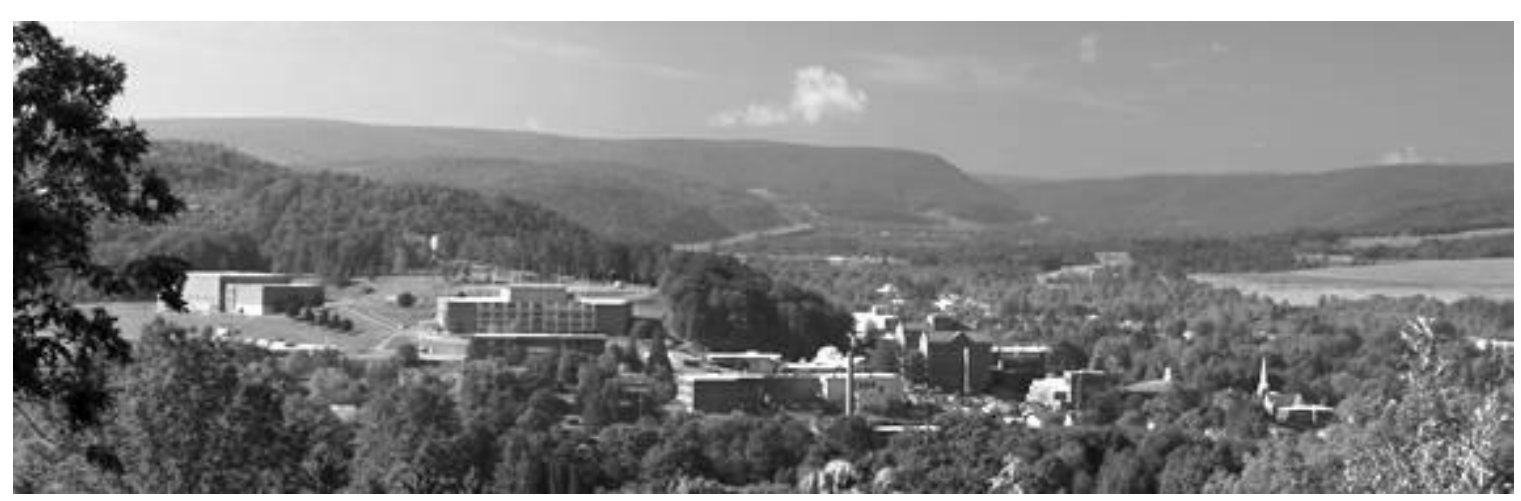

\section{Mansfield University $\bullet$ http://mansfield.edu}

Nestled in beautiful north central Pennsylvania, Mansfield University is in the middle of somewhere special. The University is surrounded by thousands of acres of state land, lakes, and spectacular mountain views - including the nearby Pine Creek Gorge - Pennsylvania's "Grand Canyon."

Our location is not the only thing that makes this place special...it's our commitment to provide you with an environment in which you can find yourself, build on your strengths, and hone those leadership skills that will carry you for a lifetime.

Want to make a difference in your world... are you looking to change the course of history? Then Mansfield may be the place for you. 


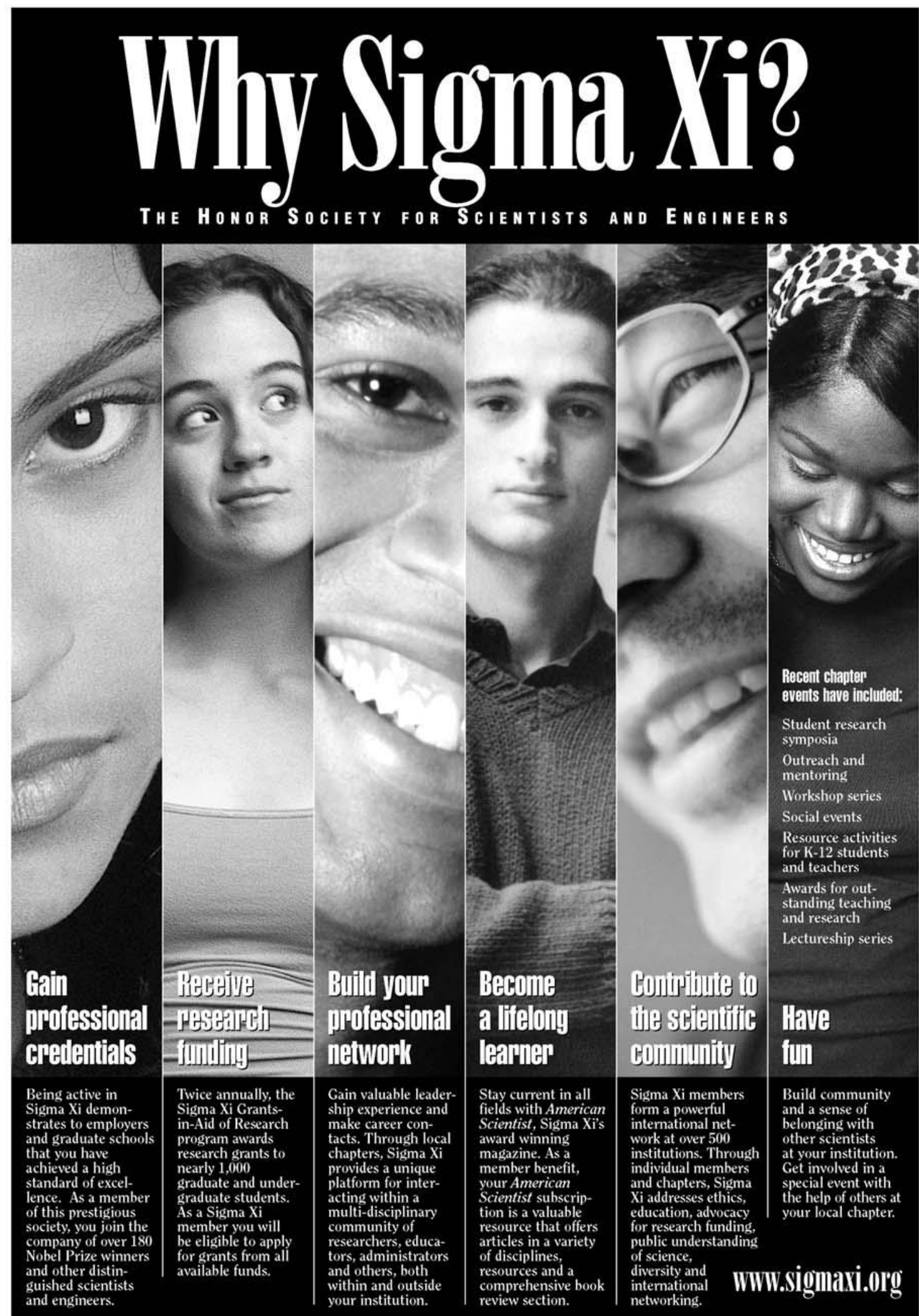

Sigma Xi, The Scientilic Research Society • 88 AlexandeP Drive • P.O. Box 13975 • Research Triangle Park, NC 27708 • 918-548-4681 • 800-243-6534 